\title{
Persistence or Clearance of Human Papillomavirus Infections in Women in Ouro Preto, Brazil
}

\author{
P. M. Miranda, ${ }^{1}$ N. N. T. Silva, ${ }^{2}$ B. C. V. Pitol, ${ }^{2}$ I. D. C. G. Silva, ${ }^{3}$ J. L. Lima-Filho, ${ }^{4}$ \\ R. F. Carvalho, ${ }^{1,5}$ R. C. Stocco, ${ }^{1,5}$ W. Beçak, ${ }^{1,6}$ and A. A. Lima ${ }^{2}$ \\ ${ }^{1}$ Laboratório de Genética, Instituto Butantan, Avenida Vital Brasil 1500, 05503-900 São Paulo, SP, Brazil \\ ${ }^{2}$ Departamento de Análises Clínicas Escola de Farmácia, Universidade de Ouro Preto (UFOP), Rua Costa Sena 171, \\ 35400-000 Ouro Preto, MG, Brazil \\ ${ }^{3}$ Laboratório de Tocoginecologia, Departamento de Ginecologia, Universidade Federal de São Paulo, 04039-032 São Paulo, SP, Brazil \\ ${ }^{4}$ Laboratório de Imunopatologia Keizo Asami (LIKA), Universidade Federal de Pernambuco (UFPE), 50670-901 Recife, PE, Brazil \\ ${ }^{5}$ Programa de Pós-Graduação Interunidades em Biotecnologia, Universidade de São Paulo, 05508-900 São Paulo, SP, Brazil \\ ${ }^{6}$ Departamento de Biologia, Universidade Federal da Integração Latino-Americana (UNILA), 85867-970 Foz do Iguaçú, PR, Brazil
}

Correspondence should be addressed to R. C. Stocco; ritastocco@butantan.gov.br

Received 2 April 2013; Accepted 6 September 2013

Academic Editor: Marcelo Palma Sircili

Copyright (C) 2013 P. M. Miranda et al. This is an open access article distributed under the Creative Commons Attribution License, which permits unrestricted use, distribution, and reproduction in any medium, provided the original work is properly cited.

\begin{abstract}
Persistent high-risk (HR) human papillomavirus (HPV) infection is necessary for development of precursor lesions and cervical cancer. We investigate persistence and clearance of HPV infections and cofactors in unvaccinated women. Cervical samples of 569 women (18-75 years), received for routine evaluation in the Health Department of Ouro Preto, Brazil, were collected and subjected to PCR (MY09/11 or GP5+/6+ primers), followed by RFLP or sequencing. All women were interviewed to collect sociodemographic and behavioral information. Viral infection persistence or clearance was reevaluated after 24 months and was observed in $59.6 \%$ and $40.4 \%$ of women, respectively. HPVs $16,33,59,66,69$, and 83 (HR) were the most persistent types whereas HPVs 31,45 , and 58 were less persistent. Clearance or persistence did not differ between groups infected by HPVs 18, 53, and 67. In low-risk (LR) types, HPV 6 infected samples were associated with clearance, while HPV 11, 61, 72, or 81 infected samples were persistent in the followup. No statistically significant association was detected between persistent HPV infections and sociodemographic and behavioral characteristics analyzed. To study persistence or clearance in HPV infection allows the identification of risk groups, cofactors, and strategies for prevention of cervical cancer.
\end{abstract}

\section{Introduction}

Human papillomavirus (HPV) infections are the most commonly diagnosed sexually transmitted disease. More than $100 \mathrm{HPV}$ types have been identified. They infect the skin squamous epithelia and mucosa and usually cause benign papillomas or warts. Persistent infection with oncogenic high-risk HPV causes all cervical cancers, most anal cancers, and a subset of vulvar, vaginal, penile, and oropharyngeal cancers [1-3].

The major steps in cervical carcinogenesis include HPV infection, HPV persistence for a certain period of time, progression to precancer, and invasion $[4,5]$.
HPV infection alone may not be sufficient to cause cervical cancer, and other factors influence the risk of progression to cervical cancer. High parity, smoking, long-term use of oral contraceptives, sexual behavior, genetic factors, and coinfection with other sexually transmitted infectious agents such as herpes simplex virus 2 (HSV-2) and Chlamydia trachomatis have been established as cofactors for cervical cancer among women with persistent infections [6-9].

Although these environmental and genetic factors are considered to act as HPV cofactors contributing to progression from viral infection to cervical cancer, few prospective studies have addressed the roles that these risk factors play in the natural history of precursor lesions. The knowledge of 
epidemiology and natural history of HPV infection (acquisition, clearance, and persistence) is relevant and can direct interventions to prevent preneoplastic lesions and cervical cancer [4].

There is evidence that most HPV infections are transient and clear spontaneously within 12-24 months after first detection. Persistent HPV infection with elevated risk of cervical cancer occurs in only a small percentage of virus infected women $[5,10]$. The reasons of this fact are still unknown.

The importance of HPV clearance/persistence has been recognized recently, and the number of studies addressing these issues has increased substantially during the past few years. However, data are still incomplete and in part inconsistent as to the cofactors that regulate these events $[11,12]$.

In Ouro Preto, MG, Brazil, a recent study showed prevalence of HPV infections in women with normal cervical cytology. Different subtypes of high-risk HPV (mainly HPV 16) were predominant. Furthermore, age, literacy, residence, marital status, smoking status, and number of sexual partners were independently associated with HPV infection [13].

$\mathrm{HPV}$-positive women in this prevalence study have been accompanied to assess the natural history of viral infection. Therefore, the aim of this study was to investigate persistence and clearance of HPV infections in unvaccinated women and cofactors correlated with such events.

\section{Material and Methods}

Ethical Statements. The protocols used in this study were approved by the Ethical Committee in Research of the Universidade Federal de São Paulo (number 0832.08) assigned by the president of this committee.

The sample was composed of 569 women (aged 18 to 75 years) living in Ouro Preto, MG, Brazil. Women were randomly selected when they visited health units for routine gynecological evaluation and they were not enrolled in the study if they were pregnant, diagnosed with mental incompetence, or diagnosed with carcinoma, except the cervical cancer. This project was reviewed and approved by the Institutional Ethic Committee, and informed consent was obtained from private interviews at the time of gynecological evaluation.

Sociodemographic characteristics, smoking status, alcohol consumption, bracken fern diet, and sexual and reproductive behavior were obtained from private interviews with the women at the time of the gynecological evaluation. Subjects were considered as nonsmokers or nonalcohol consumers if they have never smoked or drunk. Speculum examination was performed by gynecologists; cervical samples were obtained using an extended tip "Ayre" spatula. The conventional cervical smear was spread onto a glass slide and the tip of the spatula was broken off and placed in a container containing preservation solution for HPV testing.

2.1. HPV-DNA Typing. For the extraction of DNA from cervical samples, we used a GenomicPrep Blood kit (GE
Healthcare), with proteinase K digestion. HPV was detected by the amplification of DNA by using a standard polymerase chain reaction (PCR) protocol with $\mathrm{L} 1$ consensus primer pair MY09 and MY11, which promotes amplification of an approximately 450 bp product and can detect more than 40 distinct low- and high-risk genital HPV types. Positive and negative controls were used in all tests. The amplification was performed according to the following protocol: $94^{\circ} \mathrm{C}$ for $30 \mathrm{~s}$, $51.5^{\circ} \mathrm{C}$ for $30 \mathrm{~s}$, and $72^{\circ} \mathrm{C}$ for $30 \mathrm{~s}$ for 35 cycles, followed by a final step at $72^{\circ} \mathrm{C}$ for $7 \mathrm{~min}[14,15]$. The $\beta$-actin gene primers were used as internal controls.

We used RT-PCR with primers GP5+/6+ for HPV detection in samples with no conclusive diagnosis using primers MY09/11. The reactions were performed using SYBR Green PCR Master Mix (Applied Biosystems) and conducted in ABI 7000 Applied Biosystems.

HPV-DNA-positive specimens were typed by restriction fragment length polymorphism (RFLP), according to Bernard et al. 1994 [16]. Samples with positive HPV viral types not identified by RFLP were identified by sequencing of the PCR product using BigDye Terminator kit (Applied Biosystems). Sequences were generated on ABI model 377 automated sequencer (Applied Biosystems) and aligned to HPV sequences at Genbank using BioEdit Sequence Alignment Editor 7.0.9.0.

2.2. Follow-Up Study. HPV infection was detected in 133 women, who were invited to participate in a follow-up study, consisting of a second cervical scrape specimen collection 24 months from first recruitment, using the same procedure as the initial examination. 89 women $(66.9 \%)$ completed the survey and were tested for HPV in 24 months. 44 women (33.1\%) were lost in the follow-up.

After 24 months (second cervical scrape specimen for cytology and HPV testing), all women were interviewed again, with the same questionnaire used in first collection, and the information was updated.

Persistent type-specific HPV infection was defined as the detection of the same HR-HPV type at both examinations (first study and follow-up study). Clearance was defined as the proportion of women who were initially HR-HPV positive (first collection), but the same HR-HPV type was not found at the follow-up [12].

2.3. Statistical Analysis. Descriptive statistics were used for the analysis of persistence and clearance of type-specific HPV infection. Particularly, Pearson's $x^{2}$ test was used to verify the association between all independent variables and the response variable. $P<0.05$ was considered statistically significant. Statistical analyses were performed using SPSS software for Windows (version 18.0).

\section{Results and Discussion}

\subsection{Results}

3.1.1. Profile of the Initial Sample. Analyses of this study were performed with samples of 89 women, mean age of 37.7 $( \pm 12.6)$ years. 
TABLE 1: Evolution of HPV infection related to virus oncogenic risk and type of infection.

\begin{tabular}{lcccc}
\hline & Total & Clearance & $\begin{array}{c}\text { Persistence } \\
n(\%)\end{array}$ & $P$ \\
\hline Infection & & & & \\
$\quad$ Single & 80 & $34(42.5)$ & $46(57.5)$ & 0.210 \\
$\quad$ Multiple & 9 & $2(22.2)$ & $7(77.8)$ & \\
Oncogenic risk & & & & \\
LR-HPV & 17 & $5(29.4)$ & $12(70.6)$ & \\
IR-HPV & 17 & $10(58.8)$ & $7(41.2)$ & 0.082 \\
HR-HPV & 55 & $21(38.2)$ & $34(61.8)$ & \\
\hline
\end{tabular}

These samples were composed predominantly of women with the following characteristics: age $\geq 30$ years $(68.5 \%)$; resident in urban areas $(76.4 \%)$; only one sexual partner in lifetime (51.7\%); no use of oral contraceptives (52.8\%); alcohol consumption (61.8\%); 1-5 pregnancies (66.3\%); bracken fern consumption in usual diet (68.5\%); smoking (40.4\%). Only $20.2 \%$ of women in the group had early onset of sexual activity ( $\leq 15$ years)

Simple infections, by a single viral type, were predominant ( 80 women, $89.9 \%$ ) and multiple HPV infections were detected in $10.1 \%$.

High-risk (HR) HPV types (mainly HPV16) were more prevalent in the study samples. HR-HPV was detected in 55 (61.8\%) women, indeterminate risk (IR) HPV in 17 (19.1\%) and low risk (LR) in 17 (19.1\%) women.

3.1.2. Evaluation after 24-Month Follow-Up. Among the 89 women HPV positive at baseline, 53 (59.6\%) had persistent infection and $36(40.4 \%)$ had clearance of the infection after 24 months.

Table 1 shows clearance or persistence of viral infection in relation to number and risk of HPV types.

Most women with multiple infections (77.8\%) showed persistence after 24 months of follow-up. However, presence of multiple infections was not statistically associated with persistent HPV infection (Table 1).

Similarly, in relation to risk oncogenic HPV types, no statistical difference was observed between persistence of viral infection and HR-HPV types. The infection persisted after follow-up in $61.8 \%$ of samples infected by HR-HPV and in $70.6 \%$ by LR-HPV (Table 1 ).

Among specific HR-HPV types, HPV 16, 33, 59, 66, 69, and 83 were the most persistent types whereas HPVs 31, 45, and 58 were the less persistent. Clearance or persistence did not differ between groups infected by HPVs 18, 53, and 67 (Table 2).

Regarding specific LR-HPV types, HPV 6 infected samples were associated with clearance. In contrast, HPV 11, 61, 72 , or 81 infected samples were associated with persistent infections in the 24-month follow-up (Table 3).

Table 4 shows that no statistically significant association was detected between persistent HPV infections and sociodemographic and behavioral characteristics evaluated.
TABLE 2: Persistence or clearance of specific high-risk (HR) HPV infection after follow-up.

\begin{tabular}{lccc}
\hline HPV types & Clearance & Persistence & Total \\
& $n(\%)$ & $n(\%)$ & $N$ \\
\hline 16 & $12(35.3)$ & $22(64.7)$ & 34 \\
18 & $3(50)$ & $3(50)$ & 6 \\
31 & $2(100)$ & $0(0)$ & 2 \\
33 & $0(0)$ & $2(100)$ & 2 \\
45 & $1(100)$ & $0(0)$ & 1 \\
53 & $1(50)$ & $1(50)$ & 2 \\
58 & $1(100)$ & $0(0)$ & 1 \\
59 & $0(0)$ & $1(100)$ & 1 \\
66 & $0(0)$ & $1(100)$ & 1 \\
67 & $1(50)$ & $1(50)$ & 2 \\
69 & $0(0)$ & $1(100)$ & 1 \\
83 & $0(0)$ & $2(100)$ & 2 \\
HR-HPV & $21(38.2)$ & $34(61.8)$ & 55 \\
\hline
\end{tabular}

TABLE 3: Persistence or clearance of specific low-risk (LR) HPV infection after follow-up.

\begin{tabular}{lccc}
\hline HPV types & $\begin{array}{c}\text { Clearance } \\
n(\%)\end{array}$ & $\begin{array}{c}\text { Persistence } \\
n(\%)\end{array}$ & $\begin{array}{c}\text { Total } \\
N\end{array}$ \\
\hline 6 & $4(66.7)$ & $2(33.3)$ & 6 \\
11 & $0(0)$ & $2(100)$ & 2 \\
61 & $1(14.3)$ & $6(85.7)$ & 7 \\
72 & $0(0)$ & $1(100)$ & 1 \\
81 & $0(0)$ & $1(100)$ & 1 \\
LR-HPV & $5(29.4)$ & $12(70.6)$ & 17 \\
\hline
\end{tabular}

\section{Discussion}

We have analyzed the prevalence of HPV infection in women presenting normal cervical cytology [13] and in women living in rural and urban areas of Ouro Preto, MG, Brazil [17]. HPVpositive women were followed for 24 months. In general, persistence of HPV infection was $59.6 \%$ and clearance was 40.4\%. It is believed that HPV infections "clear" within 2 years in more than $90 \%$ of individuals [5, 18-20]. Therefore, the percentage of HPV clearance was low in our study but similar results were also obtained by Banura et al., 2010 [21], and Guo et al., 2010 [22].

Considering only HR-HPV infections, the persistence was $61.8 \%$ and clearance was $38.2 \%$. This result was similar to that reported in studies in Brazil [23] and other countries $[12,24,25]$.

However, unlike what is expected we observed high persistence $(70.6 \%)$ and low clearance $(29.4 \%)$ of LR-HPV infections, proportions similar to those obtained for HRHPV types. This may be due to the small number of women with each viral type or time of follow-up. Banura et al., 2010 [21], showed clearance LR-HPV ranged between 50\% and $100 \%$. Other studies also observed that clearance proportion was similar in HR-HPV and LR-HPV [21, 26]. We found 
TABLE 4: Evolution of HPV infection related to sociodemographic and behavioral characteristics.

\begin{tabular}{|c|c|c|c|c|}
\hline & $\begin{array}{l}\text { Total } \\
N\end{array}$ & $\begin{array}{c}\text { Clearance } \\
n(\%)\end{array}$ & $\begin{array}{c}\text { Persistence } \\
n(\%)\end{array}$ & $P$ \\
\hline \multicolumn{5}{|c|}{ Age groups (years) } \\
\hline$>30$ & 28 & $11(39.3)$ & $17(60.7)$ & \multirow{4}{*}{0.657} \\
\hline 30 to 39 & 20 & $7(35.0)$ & $13(65.0)$ & \\
\hline 40 to 49 & 25 & $11(44.0)$ & $14(56.0)$ & \\
\hline$>50$ & 16 & $7(40.4)$ & $9(56.3)$ & \\
\hline \multicolumn{5}{|l|}{ Residence } \\
\hline Rural & 21 & $10(47.6)$ & $11(52.4)$ & \multirow{2}{*}{0.303} \\
\hline Urban & 68 & $26(38.2)$ & $42(61.8)$ & \\
\hline \multicolumn{5}{|c|}{$\begin{array}{l}\text { Age at first intercourse } \\
\text { (years) }\end{array}$} \\
\hline$\leq 15$ & 18 & $8(44.4)$ & $10(56.6)$ & \multirow{2}{*}{0.449} \\
\hline$>15$ & 71 & $28(39.4)$ & $43(60.6)$ & \\
\hline \multicolumn{5}{|c|}{$\begin{array}{l}\text { Number of lifetime } \\
\text { sexual partners }\end{array}$} \\
\hline 1 & 46 & $18(39.1)$ & $28(60.9)$ & \multirow{3}{*}{0.051} \\
\hline 2 to 4 & 28 & $8(28.6)$ & $20(71.4)$ & \\
\hline 5 or more & 15 & $10(66.7)$ & $5(33.3)$ & \\
\hline \multicolumn{5}{|c|}{ Oral contraceptive use } \\
\hline No & 47 & $19(40.4)$ & $28(59.6)$ & \multirow{2}{*}{0.583} \\
\hline Yes & 42 & $17(40.5)$ & $25(59.5)$ & \\
\hline \multicolumn{5}{|l|}{ Parity } \\
\hline 0 & 19 & $8(42.1)$ & $11(57.9)$ & \multirow{3}{*}{0.509} \\
\hline 1 to 5 & 59 & $25(42.4)$ & $34(57.6)$ & \\
\hline 6 or more & 11 & $3(27.3)$ & $8(72.7)$ & \\
\hline \multicolumn{5}{|l|}{$\begin{array}{l}\text { Bracken fern } \\
\text { consumption }\end{array}$} \\
\hline No & 28 & $12(42.9)$ & $16(57.1)$ & \multirow{2}{*}{0.466} \\
\hline Yes & 61 & $24(39.3)$ & $37(60.7)$ & \\
\hline \multicolumn{5}{|l|}{ Smoking } \\
\hline No & 53 & $19(35.8)$ & $34(64.2)$ & \multirow{2}{*}{0.197} \\
\hline Yes & 36 & $17(47.2)$ & $19(52.8)$ & \\
\hline \multicolumn{5}{|c|}{ Alcohol consumption } \\
\hline No & 34 & $13(38.2)$ & $21(61.8)$ & \multirow{2}{*}{0.457} \\
\hline Yes & 55 & $23(41.8)$ & $32(58.2)$ & \\
\hline
\end{tabular}

that HPV 16, 33, 59, 66, 69, and 83 infections were the most persistent. Studies have reported that HPV 16 was significantly more likely to persist than were all other viral types [21, 25, 27]. Moreover, Sammarco et al., 2013 [12], observed that HPV types with the highest likelihood of persistence were 31, 39, and 73, whilst HPV 16 was the least persistent. Persistent infections have a higher risk of progression to precursor lesions and cervical cancer.

In this study, most of women with multiple infections showed persistence after 24 months of follow-up. Similar results were obtained by Trottier et al., 2008 [28], Nielsen et al., 2010 [27], Castle et al., 2011 [29], and Schmeink et al., 2013 [26], who reported that infection with multiple HPV types is associated with longer persistence of HPV infection. This association was not observed by Sammarco et al., 2013 [12].

In the literature, associations of HPV persistence or clearance with cofactors vary widely due to the sample size, population characteristics, and study design. In this study, there was no significant association between HPV persistence or clearance and the analyzed cofactors. Schmeink et al., 2013 [26], suggest that HPV clearance is mainly related to the host immune response or other intrinsic host factors and not to present behavior factors.

There are reports that women with persistent HR-HPV infections were younger than those who cleared their infections $[12,30,31]$. Others showed that persistence increased with age [29]. However, no association between HPV persistence and age was found in this study as in Trottier et al., 2008 [28], and Muoz et al., 2009 [32].

Likewise in this work, some studies found no association between persistent HPV infection and smoking, number of sexual partners, oral contraceptive use, and high parity [12, 26, 27, 30, 33].

Persistent high-risk HPV infection also was associated with high viral load $[22,34]$.

The main limitations of this study were sample size and follow-up period. This prevented extensive discussion of some results and direct comparison with other studies. Furthermore, it is important to emphasize that our data were based solely on the detection of DNA in cervical samples.

HR-HPV persistence plays a key role in the progression of preneoplastic lesions and in the development of cervical cancer. Thus, epidemiological and biological understanding of the natural history of HPV infection is critical to guide the implementation of strategies for prevention and control of cervical cancer.

\section{Conflict of Interests}

All authors declare that there is no conflict of interests regarding the research, authorship, and/or publication of this paper. The authors inform that all materials and trademarks mentioned were used just as part of experimental protocol and there are no financial gains or favoritism of business.

\section{Acknowledgments}

The authors would like to thank the Ministério de Ciência, Tecnologia e Inovação/Conselho Nacional de Desenvolvimento Científico e Tecnológico (CNPq Proc. 554816/2006-7), PRONEX/ FACEPE (APQ-0781-4.01/06), FAPESP (Proc. 2006/024396), FAPEMIG, Fundação Butantan, and Coordenação de Aperfeiçoamento Pessoal de Nível Superior (CAPES) for the financial support and thank Carolina da Paz Sabino for her editorial support.

\section{References}

[1] H. Z. Hausen, "Papillomaviruses and cancer: from basic studies to clinical application," Nature Reviews Cancer, vol. 2, no. 5, pp. 342-350, 2002. 
[2] M. Steben and E. Duarte-Franco, "Human papillomavirus infection: epidemiology and pathophysiology," Gynecologic Oncology, vol. 107, no. 2, pp. S2-S5, 2007.

[3] H. Z. Hausen, "Human papillomavirus and cervical cancer," Indian Journal of Medical Research, vol. 130, no. 3, p. 209, 2009.

[4] M. Schiffman, N. Wentzensen, S. Wacholder, W. Kinney, J. C. Gage, and P. E. Castle, "Human papillomavirus testing in the prevention of cervical cancer," Journal of the National Cancer Institute, vol. 103, no. 5, pp. 368-383, 2011.

[5] P. E. Gravitt, "The known unknowns of HPV natural history," Journal of Clinical Investigation, vol. 121, no. 12, pp. 4593-4599, 2011.

[6] X. Castellsagué and N. Muñoz, "Chapter 3: cofactors in human papillomavirus carcinogenesis-role of parity, oral contraceptives, and tobacco smoking," Journal of the National Cancer Institute Monographs, no. 31, pp. 20-28, 2003.

[7] L. A. Dahlström, K. Andersson, T. Luostarinen et al., "Prospective seroepidemiologic study of human papillomavirus and other risk factors in cervical cancer," Cancer Epidemiology Biomarkers and Prevention, vol. 20, no. 12, pp. 2541-2550, 2011.

[8] H. Yetimalar, B. Kasap, K. Cukurova, A. Yildiz, A. Keklik, and F. Soylu, "Cofactors in human papillomavirus infection and cervical carcinogenesis," Archives of Gynecology and Obstetrics, vol. 285, no. 3, pp. 805-810, 2012.

[9] K. E. Jensen, S. Schmiedel, B. Norrild, K. Frederiksen, T. Iftner, and S. K. Kjaer, "Parity as a cofactor for high-grade cervical disease among women with persistent human papillomavirus infection: a 13-year follow-up," The British Journal of Cancer, vol. 108, no. 1, pp. 234-239, 2013.

[10] K. Syrjänen, "Mechanisms and predictors of high-risk human papillomavirus (HPV) clearance in the uterine cervix," European Journal of Gynaecological Oncology, vol. 28, no. 5, pp. 337351, 2007.

[11] M. Confortini, F. Carozzi, M. Zappa et al., "Human papillomavirus infection and risk factors in a cohort of Tuscan women aged 18-24: results at recruitment," BMC Infectious Diseases, vol. 10 , article 157, 2010.

[12] M. L. Sammarco, I. Del Riccio, M. Tamburro, G. M. Grasso, and G. Ripabelli, "Type-specific persistence and associated risk factors of human papillomavirus infections in women living in central Italy," European Journal of Obstetrics and Gynecology and Reproductive Biology, vol. 168, no. 2, pp. 222-226, 2013.

[13] P. M. Miranda, B. C. Pitol, M. S. Moran et al., "Human papillomavirus infection in Brazilian women with normal cervical cytology," Genetics and molecular research, vol. 11, no. 2, pp. 1752-1761, 2012.

[14] M. H. Schiffman, H. M. Bauer, A. T. Lorincz et al., "Comparison of Southern blot hybridization and polymerase chain reaction methods for the detection of human papillomavirus DNA," Journal of Clinical Microbiology, vol. 29, no. 3, pp. 573-577, 1991.

[15] W. G. Qu, G. Jiang, Y. Cruz et al., "PCR detection of human papillomavirus: comparison between MY09/MY11 and GP5+/GP6+ primer systems," Journal of Clinical Microbiology, vol. 35, no. 6, pp. 1304-1310, 1997.

[16] H. U. Bernard, S. Y. Chan, M. M. Manos et al., "Identification and assessment of known and novel human papillomaviruses by polymerase chain reaction amplification, restriction fragment length polymorphisms, nucleotide sequence, and phylogenetic algorithms," Journal of Infectious Diseases, vol. 170, no. 5, pp. 1077-1085, 1994.
[17] B. C. V. Pitol, P. M. Miranda, M. S. Moran et al., "Prevalence of HPV infection and risk factors in rural and urban women," Unpublished results.

[18] E. L. Franco, L. L. Villa, J. P. Sobrinho et al., "Epidemiology of acquisition and clearance of cervical human papillomavirus infection in women from a high-risk area for cervical cancer," Journal of Infectious Diseases, vol. 180, no. 5, pp. 1415-1423, 1999.

[19] C. B. J. Woodman, S. Collins, H. Winter et al., "Natural history of cervical human papillomavirus infection in young women: a longitudinal cohort study," The Lancet, vol. 357, no. 9271, pp. 1831-1836, 2001.

[20] N. Muñoz, F. Méndez, H. Posso et al., "Incidence, duration, and determinants of cervical human papillomavirus infection in a cohort of Colombian women with normal cytological results," Journal of Infectious Diseases, vol. 190, no. 12, pp. 2077-2087, 2004.

[21] C. Banura, S. Sandin, L. van Doorn et al., "Type-specific incidence, clearance and predictors of cervical human papillomavirus infections (HPV) among young women: a prospective study in Uganda," Infectious Agents and Cancer, vol. 5, no. 1, article 7, 2010.

[22] Y. Guo, K. You, J. Qiao, Y. Zhao, C. Liu, and L. Geng, "Natural history of infections with high-risk HPV in Chinese women with abnormal cervical cytology findings at baseline," International Journal of Gynecology and Obstetrics, vol. 110, no. 2, pp. 137-140, 2010.

[23] M. I. Rosa, J. M. G. Fachel, D. D. Rosa, L. R. Medeiros, C. N. Igansi, and M. C. Bozzetti, "Persistence and clearance of human papillomavirus infection: a prospective cohort study," The American Journal of Obstetrics and Gynecology, vol. 199, no. 6, pp. 617.el-617.e7, 2008.

[24] E. R. Howe, Z. Li, R. C. McGlennen, W. L. Hellerstedt, and L. S. Downs Jr., “Type-specific prevalence and persistence of human papillomavirus in women in the United States who are referred for typing as a component of cervical cancer screening," The American Journal of Obstetrics and Gynecology, vol. 200, no. 3, pp. 245.e1-245.e7, 2009.

[25] X. Carcopino, N. Bolger, M. Henry et al., "Evaluation of type-specific HPV persistence and high-risk HPV viral load quantitation in HPV positive women under 30 with normal cervical cytology," Journal of Medical Virology, vol. 83, no. 4, pp. 637-643, 2011.

[26] C. E. Schmeink, L. F. Massuger, C. H. Lenselink et al., "Prospective follow-up of 2, 065 young unscreened women to study human papillomavirus incidence and clearance," International Journal of Cancer, vol. 133, no. 1, pp. 172-181, 2013.

[27] A. Nielsen, S. K. Kjaer, C. Munk, M. Osler, and T. Iftner, "Persistence of high-risk human papillomavirus infection in a population-based cohort of Danish women," Journal of Medical Virology, vol. 82, no. 4, pp. 616-623, 2010.

[28] H. Trottier, S. Mahmud, J. C. M. Prado et al., “Type-specific duration of human papillomavirus infection: implications for human papillomavirus screening and vaccination," Journal of Infectious Diseases, vol. 197, no. 10, pp. 1436-1447, 2008.

[29] P. E. Castle, A. C. Rodríguez, R. D. Burk et al., "Longterm persistence of prevalently detected human papillomavirus infections in the absence of detectable cervical precancer and cancer," Journal of Infectious Diseases, vol. 203, no. 6, pp. 814822, 2011.

[30] S. Syrjänen, I. Shabalova, N. Petrovichev et al., "Factors predicting persistence of high-risk human papillomavirus (HPV) infections in women prospectively followed-up in three new 
independent states (NIS) of the former Soviet Union," European Journal of Gynaecological Oncology, vol. 26, no. 5, pp. 491-498, 2005.

[31] E. Fukuchi, G. F. Sawaya, M. Chirenje et al., "Cervical human papillomavirus incidence and persistence in a cohort of HIVnegative women in zimbabwe," Sexually Transmitted Diseases, vol. 36, no. 5, pp. 305-311, 2009.

[32] N. Muoz, G. Hernandez-Suarez, F. Méndez et al., "Persistence of HPV infection and risk of high-grade cervical intraepithelial neoplasia in a cohort of Colombian women," The British Journal of Cancer, vol. 100, no. 7, pp. 1184-1190, 2009.

[33] N. Muñoz and R. Herrero, "Prevention of cervical cancer in women's hands: Mexico leads the way," The Lancet, vol. 378, no. 9806, pp. 1829-1831, 2011.

[34] J. Bae, S. Seo, Y. Park et al., "Natural history of persistent high-risk human papillomavirus infections in Korean women," Gynecologic Oncology, vol. 115, no. 1, pp. 75-80, 2009. 


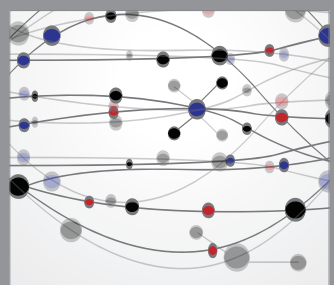

The Scientific World Journal
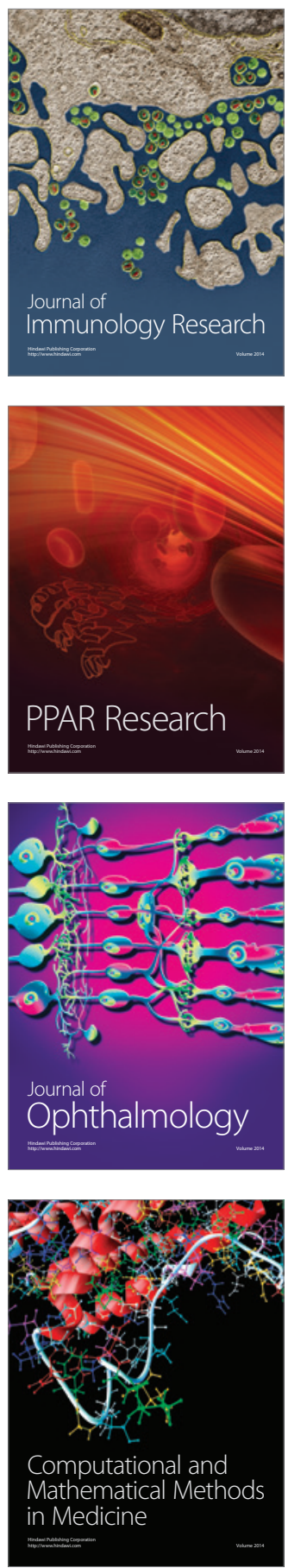

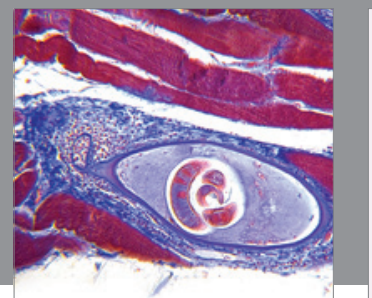

Gastroenterology

Research and Practice
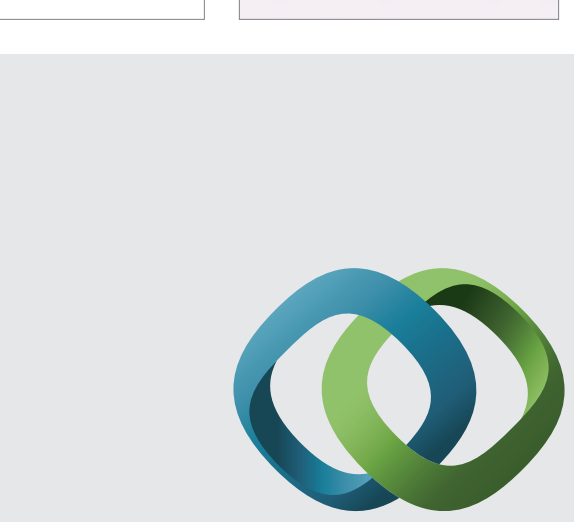

\section{Hindawi}

Submit your manuscripts at

http://www.hindawi.com
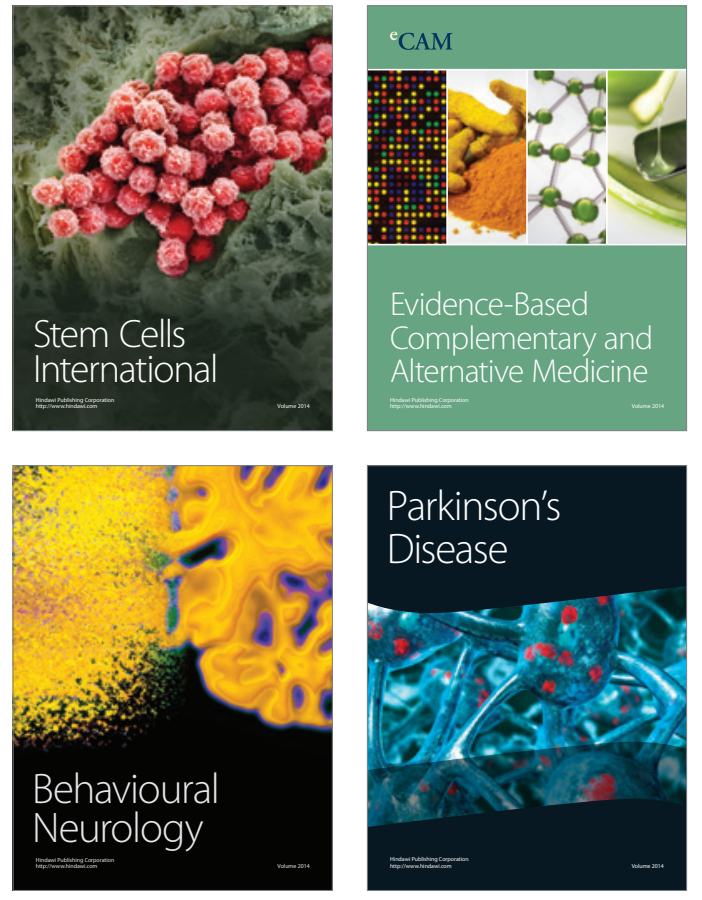
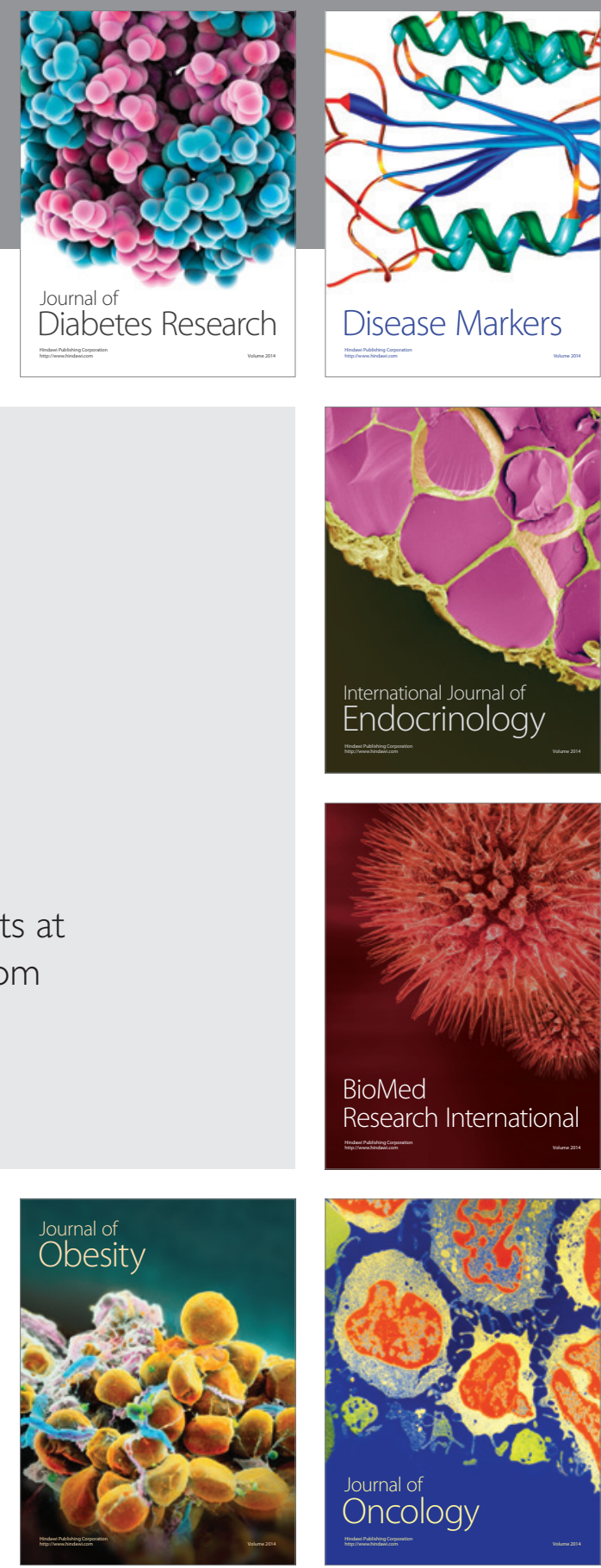

Disease Markers
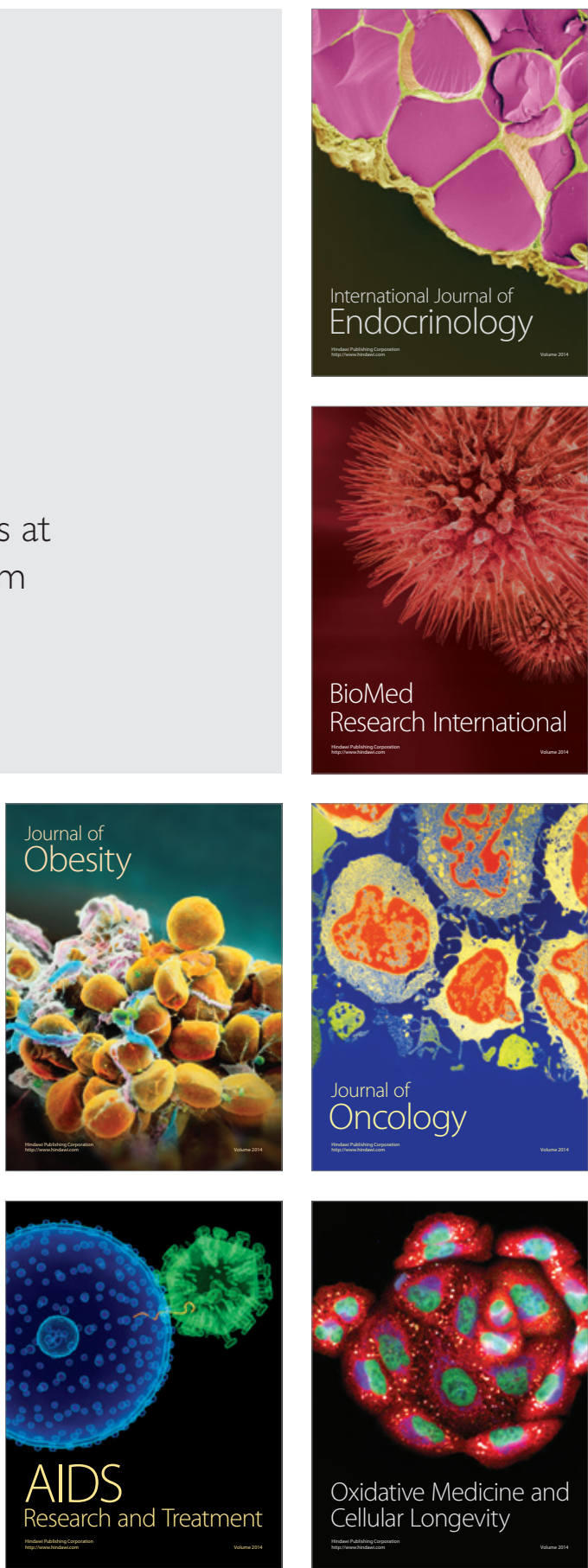